\title{
IN SITU ALLELOPATHIC POTENTIAL OF MYRIOPHYLLUM VERTICILLATUM (HALORAGACEAE) AGAINST SELECTED PHYTOPLANKTON SPECIES ${ }^{1}$
}

\author{
Sabine Hilt (nee Körner) ${ }^{2}$ \\ Leibniz-Institute of Freshwater Ecology and Inland Fisheries, Müggelseedamm 301, 12587 Berlin, Germany \\ Mary G. N. Ghobrial \\ National Institute of Oceanography and Fisheries, Kayed Bay, Anfoushy, Alexandria, Egypt
}

and

Elisabeth M. Gross

Limnological Institute, Biology, University of Konstanz, PO Box 5560 M659, 78457 Konstanz, Germany

The potential allelopathic impact of Myriophyllum verticillatum $\mathrm{L}$. under in situ conditions was determined in a series of field and laboratory experiments. Coexistence experiments were performed in a lake dominated by $M$. verticillatum (Van Goor) Meffert where we exposed three unialgal phytoplankton cultures in dialysis tubes to macrophyte exudates regularly during the vegetated period. Plant content and exudation of polyphenolic compounds were determined, and the inhibitory activity of polyphenol-containing extracts was tested in bioassays with cyanobacteria. To account for possible resource interference, we monitored growth and photosynthesis of phosphorus-limited and unlimited cyanobacterium Limnothrix redekei in dialysis tubes exposed to M. verticillatum in aquaria.

A high allelopathic potential of $M$. verticillatum was concluded from high tissue concentrations of total phenolic compounds of $6 \%-12 \%$ of dry matter, the demonstrated release of bioactive polyphenols into the surrounding medium, and the inhibition of cyanobacteria by extracts. We could not unambiguously demonstrate the exudation of polyphenols by $M$. verticillatum in situ due to interference with allochthonous humic compounds. In laboratory experiments, $L$. redekei exhibited significantly reduced maximum relative electron transport rates when co-cultivated in dialysis tubes with $M$. verticillatum. The field dialysis tube experiment confirmed this result, accompanied by a decline of $\operatorname{chl} a$ and PSII activity for $L$. redekei and the diatom Stephanodiscus minutulus (Kütz.) Greve et Möller, but not for the green alga Scenedesmus armatus Chodat in August. At other times, either no effects or stimulatory effects were observed with all species. Nutrient limitation of the target species may have masked allelopathic effects, and $M$. verticillatum may have enhanced phytoplankton growth due to phosphorus leakage.

\footnotetext{
${ }^{1}$ Received 12 October 2005. Accepted 1 September 2006.

${ }^{2}$ Author for correspondence: e-mail hilt@igb-berlin.de.
}

Key index words: allelopathy; Myriophyllum verticillatum; PAM-fluorometry; photosynthesis; shallow lakes; submerged macrophytes

Abbreviations: $\alpha$, initial slope of photosynthesis versus irradiance curves; ADA, agar diffusion assay; APA, alkaline phosphatase activity; dm, dry mass; P, phosphorus; PAM, pulse amplitude modulated; PAR, photosynthetically active radiation; rETR, relative electron transport rate; TPC, total phenolic compounds

Allelopathic growth inhibition of phytoplankton by submerged macrophytes may confer an advantage to angiosperms in the competition for light, carbon, and nutrients (Gross 2003a). Allelopathic inhibition of phytoplankton is one of the mechanisms thought to stabilize the macrophyte-dominated clear-water state in shallow eutrophic lakes (Phillips et al. 1978, Scheffer 1998). Despite experimental demonstration of the presence of inhibiting substances in selected macrophytes (Anthoni et al. 1980, Wium-Andersen et al. 1983, Aliotta et al. 1992, Gross et al. 1996) and their release and mode of activity in laboratory studies (Nakai et al. 1999, Körner and Nicklisch 2002, Leu et al. 2002), the ecological relevance of allelopathic interactions between submerged macrophytes and phytoplankton is still unclear (Gross 2003a). Eurasian watermilfoil, Myriophyllum spicatum L., is one of the best investigated species among allelopathically active submerged macrophytes. It exhibits a strong inhibitory action against various cyanobacteria, and to a lesser extent to chlorophytes and diatoms (Gross et al. 1996, Körner and Nicklisch 2002). The hydrolyzable polyphenol tellimagrandin II was determined to be the main inhibitory substance (Gross et al. 1996). Whorled watermilfoil, $M$. verticillatum L., occurring primarily in less calcareous lakes, also contains algicidal phenolic compounds (Aliotta et al. 1992). Its allelopathic activity, however, has not yet been shown in coexistence experiments or under in situ conditions. 
According to Willis (1985), six prerequisites have to be met to show unequivocally the occurrence of allelopathy: (1) a pattern of inhibition of target plant(s) or alga(e), (2) allelopathical compound(s) produced by donor plants, (3) the release of these compounds by the producing plant, (4) their transport and/or accumulation in the environment, (5) the uptake by the target organism(s), and (6) that the inhibition cannot be explained solely by other physical or biotic factors, especially herbivory and competition. Gross et al. (in press) therefore recommended multiple-approach allelopathy investigations. One of the main problems of in situ studies on allelopathic interactions is the interference with nutrients. Nutrient availability might impact both the resource allocation of macrophytes to growth versus production of allelochemicals (Gross $2003 \mathrm{~b}$ ) as well as the competition between macrophytes and phytoplankton. Although rooted macrophytes can obtain all nutrients from sediments (Barko and Smart 1980), foliar uptake becomes increasingly important as nutrient concentrations in the water column increase (Carignan 1982, Rattray et al. 1991). Several authors (Fitzgerald 1969, Van Donk et al. 1993, Kufel and Ozimek 1994) hypothesized that macrophytes may limit phytoplankton by nutrient uptake from the water. Lombardo and Cooke (2003), however, stressed that direct competition for phosphorus $(\mathrm{P})$ does not contribute to medium- and long-term phytoplankton inhibition in lakes rich in the nonrooted Ceratophyllum demersum L. Living aquatic plants, on the other hand, continuously leak ions and organic compounds from their tissues (DeMarte and Hartman 1974, Jackson et al. 1994) and may therefore also support phytoplankton growth. Van Donk and Van de Bund (2002) concluded that macrophytes have the potential to both reduce and increase nutrient levels in shallow lakes. Neither nutrient limitation nor excess nutrient availability through macrophyte leakage should occur when comparing phytoplankton growth in macrophyte stands with that of control sites to demonstrate allelopathic effects.

In order to gain information on the potential in situ allelopathic impact of whorled milfoil on phytoplankton, we combined field and laboratory experiments. Our sampling site was a small sheltered lake containing a small but dense stand of $M$. verticillatum in a shallow bay. We measured the seasonal variation of total phenolic compounds (TPC) in M. verticillatum plants and of TPC exuded into the surrounding water to show that allelochemicals are produced by $M$. verticillatum and released into the water [prerequisites (2) and (3) of Willis 1985]. For comparison, we used lake water from a site without plants. In the laboratory, we measured TPC excretion rates of the plants and tested the inhibitory activity of crude plant extracts in a bioassay [prerequisite (1)]. Extract-based methods offer the chance to compare the allelopathic potential of different macrophyte species and seasonal differences in one species in a standardized way. Such studies, however, should only be presented accompanied by experiments using exudates or coexistence experiments (Gross et al. in press). We therefore conducted in situ coexistence experiments using unialgal cultures of three taxonomically divergent phytoplankton species as common representatives of these functional groups-the cyanobacterium Limnothrix redekei, the diatom Stephanodiscus minutulus, and the green alga Scenedesmus armatus. L. redeke $i$ is known to be very sensitive against the impact of $M$. spicatum, while the two eukaryotic algae exhibit moderate to low sensitivity toward this macrophyte (Körner and Nicklisch 2002). With all target species, growth rates and photosynthetic parameters using pulse amplitude-modulated (PAM) fluorometry (Schreiber et al. 1994) were compared when grown in dialysis tubes between and outside the $M$. verticillatum stands within the same lake at different times of the vegetated period. To evaluate the potential role of P-limitation in our field study, we conducted an additional laboratory experiment using P-limited and unlimited cultures of L. redekei.

\section{MATERIALS AND METHODS}

$T P C$ in plants and water. M. verticillatum shoots (10 shoots of $25 \mathrm{~cm}$ length, three replicates from two different sites per month) as well as $1 \mathrm{~L}$ water samples (three replicates in open water and $M$. verticillatum stands, respectively) were collected in Lake Krumme Laake (Berlin, Germany) monthly between May and September 2004. This lake has an area of about 1 ha and is fed only by rain and groundwater. A $200 \mathrm{~m}^{2} M$. verticillatum stand in a shallow bay is the only submerged macrophyte species present in the lake. For each of the total six samples per month, plants were dissected into apical tips, leaves, and stems; shock-frozen in liquid nitrogen; freezedried; and homogenized. This material was extracted for $2 \mathrm{~h}$ at $16^{\circ} \mathrm{C}$ with $50 \%$ aqueous acetone. The extracts were analyzed for TPC using the Folin-Ciocalteau assay (method modified after Gross et al. 1996, using only two-fifths of the given volume for sample and reagents). To test for the proportion of nonphenolic compounds reacting with the Folin reagent, TPC of extracts were measured again after treatment with polyvinyl polypyrrolidone (PVPP), which mimics proteins and precipitates phenolics (Loomis and Battaile 1966). Fifty microliters of a PVPP suspension $\left(0.1 \mathrm{~g} \cdot \mathrm{mL}^{-1}\right.$ PVPP; Sigma Inc., St. Louis, MO, USA, P6755; in ultrapure water) was added to $50 \mu \mathrm{L}$ of extract [raw extract dried in vacuo and resuspended in 50\% methanol (v/v) in water] and shaken for $2 \mathrm{~h}$ at $14^{\circ} \mathrm{C}$. Each month, three samples of 10 shoots were incubated for 12:12 light:dark (L:D) cycle at about $330 \mu \mathrm{mol}$ photons $\cdot \mathrm{m}^{-2} \cdot \mathrm{s}^{-1}$ and a temperature of $20 \pm 1^{\circ} \mathrm{C}$ in $1 \mathrm{~L}$ fish test water (DIN EN ISO 7346-3: $294 \mathrm{mg} \cdot \mathrm{L}^{-1} \quad \mathrm{CaCl}_{2} \cdot 2 \mathrm{H}_{2} \mathrm{O} ; 123.3 \mathrm{mg} \cdot \mathrm{L}^{-1} \quad \mathrm{MgSO}_{4} \cdot 7 \mathrm{H}_{2} \mathrm{O}$; $63 \mathrm{mg} \cdot \mathrm{L}^{-1} \mathrm{NaHCO}_{3} ; 5.5 \mathrm{mg} \cdot \mathrm{L}^{-1} \mathrm{KCl}$; plants upside down with stem ends outside the water) to follow excretion of phenolic compounds into the surrounding medium. Afterwards, plants were dried until weight constancy, and dry mass $(\mathrm{dm})$ was determined.

Water samples of Lake Krumme Laake and incubation medium of $M$. verticillatum from laboratory experiments were acidified to $\mathrm{pH} 4$ using acetic acid to enhance binding of phenolic compounds. They were then filtered through washed GF/ F filters (Whatman, Maidstone, UK) to remove particles and passed over preconditioned $\varnothing 47 \mathrm{~mm} \mathrm{C}_{18}$ high-performance extraction disks (3 M Empore ${ }^{\mathrm{TM}}$, 3M, St. Paul, MN, USA). Lipophilic compounds adsorbed to the disks were eluted twice with $10 \mathrm{~mL}$ methanol, and both elutions were combined, dried 
in a rotary evaporator, and resuspended in $2 \mathrm{~mL}$ of $50 \%$ methanol. TPC of this concentrated exudate was determined using the Folin-Ciocalteau assay. The means of TPC in different plant parts as well as in lake water of control and $M$. verticillatum sites were compared using a two-way analysis of variance (ANOVA) with the statistical package SPSS. Subsequent multiple comparisons using Tukey' post hoc test were conducted between means of TPC in plants and water for the different months. The means of the culture medium containing excreted TPC were compared using a one-way ANOVA.

Bioassay with plant extracts. The inhibitory activity of crude extracts of the apical parts of $M$. verticillatum in $50 \%$ methanol was tested against the cyanobacterium Anabaena PCC 7120 using an agar diffusion assay (ADA). The cultivation of the test organism and the preparation of the ADA were performed as described in Gross et al. (1991). Three different amounts of crude methanolic extracts representing $0.5,1$ and $2 \mathrm{mg}$ plant $\mathrm{dm}$ were spotted on plates of medium solidified with $1 \%$ agar (three replicates per month). The plate was then overlaid with $10 \mathrm{~mL}$ of a suspension of Anabaena spp. (at optical densities of 0.04 absorption units) in cyanobacteria medium containing $1 \%$ agar. Inhibitory activities could be seen by an area of clearing around cell inocula or spots after 1 week of incubation at $28^{\circ} \mathrm{C}$ and constant illumination $\left(80 \mu \mathrm{mol}\right.$ photons $\left.\cdot \mathrm{m}^{-2} \cdot \mathrm{s}^{-1}\right)$. The inhibitory effects were quantified by measuring the diameter and calculating the area of the clearing zones. The influence of crude extracts on the growth of the cyanobacterium was assessed by means of one-way ANOVA and subsequent multiple comparisons using Tukey' post hoc tests when the ANOVA revealed significant effects.

In situ experiments. To test the in situ influence of $M$. verticillatum on different planktonic algae and cyanobacteria, $50 \mathrm{~mL}$ of unialgal cultures of the cyanobacterium $L$. redekei HUB 010, the diatom Stephanodiscus minutulus HUB 082, and the green alga Scenedesmus armatus HUB 041 were put in sterile dialysis membrane tubes (method following Körner and Nicklisch 2002) and placed in M. verticillatum stands of Lake Krumme Laake and a control site without submerged plants (three replicates each) for 3 days. Sterile dialysis membrane tubes were prepared using regenerated cellulose Wienie-Pak Skinless Sausage Casings (DevroTeepak, Scarborough, ON, Canada) with a molecular weight cutoff of 7000 . Membranes were washed with distilled water and knotted close at both ends. An air bubble kept the dialysis tubes floating at the water surface to prevent differences in light availability for the algae and cyanobacteria between the plant and the control site. The starting concentration and growth conditions are given in Table 1. Phytoplankton strains were obtained from the culture collection of the Humboldt University in Berlin (HUB), Germany, and were kept in a modified M III nutrient solution (Nicklisch 1992, Körner and Nicklisch 2002). Nitrogen and P concentrations were kept high $\left(42.5 \mathrm{mg} \cdot \mathrm{L}^{-1} \quad \mathrm{NaNO}_{3}\right.$, $6.8 \mathrm{mg} \cdot \mathrm{L}^{-1} \mathrm{KH}_{2} \mathrm{PO}_{4}$ ) to allow storage of nutrients in the test algae and cyanobacteria to maintain growth during the 3 days of the experiment, because the dialysis tubes cannot retain nutrients and nutrient concentrations in the lake can potentially become limiting. The starting concentrations of chl $a$ were low (Table 1). At day 3 , we measured chl $a$, PSII activity, and relative electron transport rate ( $\mathrm{rETR}$ ) versus PAR curves (so-called rapid light curves) after 20 min of dark adaptation using a Phyto-PAM ${ }^{\mathbb{R}}$ Fluorometer (Heinz Walz GmbH, Effeltrich, Germany, www.walz.com/over7.htm; Schreiber 1986). A detailed description of the method can be found in Körner and Nicklisch (2002). The means were compared between control and $M$. verticillatum treatments using Student's $t$-test with the statistical package SPSS. The experiments were performed monthly between June and September 2004, when $M$. verticillatum plants fully filled the water column in their stand in Lake Krumme Laake. Macronutrient concentrations of the lake water were determined at the end of each experiment following Anonymous (1999) in both water of the macrophyte stands and control sites.

Laboratory experiments on interference with P-limitation. To test the influence of P-limitation on the allelopathic interaction, we grew L. redekei $(50 \mathrm{~mL})$ in dialysis membrane tubes (three replicates) with and without the influence of $M$. verticillatum in $4 \mathrm{~L}$ aquaria containing $\mathrm{M}$ III nutrient solution $\left(42.5 \mathrm{mg} \cdot \mathrm{L}^{-1} \mathrm{NaNO}_{3}, 6.8 \mathrm{mg} \cdot \mathrm{L}^{-1} \mathrm{KH}_{2} \mathrm{PO}_{4}\right)$ with and without $\mathrm{P}$ for 3 days following the method described in Körner and Nicklisch (2002). Twenty $25 \mathrm{~cm}$ long $M$. verticillatum shoots from Lake Krumme Laake were placed upside down into the water, resulting in a biomass of $1.2 \mathrm{~g} \mathrm{dm} \cdot \mathrm{L}^{-1}$, which is comparable with natural lake conditions. Milfoils can reach densities up to $1200 \mathrm{~g} \mathrm{dm} \cdot \mathrm{m}^{-2}$ (Grace and Wetzel 1978). When applying P-limitation, the lower ends of the stems were placed into nutrient-rich agar, but the agar did not touch the water to prevent $\mathrm{P}$ from leaking directly from the agar into the water. This approach simulates conditions in lakes when rooted plants take up nutrients from the nutrient-rich sediment whereas P-limitation occurs in the surrounding water. Aquaria containing plastic plants (to simulate the shading effect) were used as controls. Light was supplied by fluorescent tubes (Osram Biolux, Munich, Germany) with a daylightsimilar emission spectrum. A scalar irradiance (PAR) of about $330 \mu \mathrm{mol}$ photons $\cdot \mathrm{m}^{-2} \cdot \mathrm{s}^{-1}$ at a light period of $12 \mathrm{~h} /$ day and a temperature of $20 \pm 1^{\circ} \mathrm{C}$ were maintained. Chl $a$, PSII activity, rapid light curves, and the alkaline phosphatase activity (APA) of $L$. redekei were recorded daily (APA in experiment without P-limitation only at day 3) from subsamples and compared between control and $M$. verticillatum treatment. APA was measured by fluorescence spectrometry with methylumbelliferyl-phosphate as a substrate (see Gross et al. 1996) and calculated per chl $a$. The means of the 4 days and two treatments were compared using a repeated measures

TABLE 1. Chlorophyll $a$ content $( \pm \mathrm{SE}, n=3)$ of the investigated phytoplankton species at the beginning of the in situ experiments and growth conditions in Lake Krumme Laake.

\begin{tabular}{|c|c|c|c|c|c|c|c|c|c|}
\hline & \multirow[b]{2}{*}{$\begin{array}{l}\text { Limnothrix } \\
\text { redekei }\end{array}$} & \multicolumn{2}{|c|}{$\mathrm{Chl} a\left(\mu \mathrm{g} \cdot \mathrm{L}^{-1}\right)$} & \multirow[b]{2}{*}{$\begin{array}{c}\text { Water } \\
\text { temperature } \\
\left({ }^{\circ} \mathrm{C}\right)\end{array}$} & \multirow[b]{2}{*}{$\mathrm{pH}$} & \multirow[b]{2}{*}{$\begin{array}{l}\text { Conductivity } \\
\left(\mu \mathrm{S} \cdot \mathrm{m}^{-2}\right)\end{array}$} & \multirow[b]{2}{*}{$\begin{array}{l}\text { Oxygen } \\
\text { content } \\
\left(\mathrm{mg} \cdot \mathrm{L}^{-1}\right)\end{array}$} & \multirow[b]{2}{*}{$\begin{array}{c}\text { Total } \\
\text { phosphorus } \\
\left(\mu \mathrm{g} \cdot \mathrm{L}^{-1}\right)\end{array}$} & \multirow[b]{2}{*}{$\begin{array}{c}\text { Total } \\
\text { nitrogen } \\
\left(\mathrm{mg} \cdot \mathrm{L}^{-1}\right)\end{array}$} \\
\hline & & $\begin{array}{l}\text { Stephanodiscus } \\
\text { minutulus }\end{array}$ & $\begin{array}{l}\text { Scenedesmus } \\
\text { armatus }\end{array}$ & & & & & & \\
\hline June & $7.1 \pm 0.2$ & $6.6 \pm 0.2$ & $6.7 \pm 0.2$ & 19.7 & 7.6 & 155 & $8.8 / 8.3$ & $30 \pm 2.3$ & $1.2 \pm 0$ \\
\hline July & $3.8 \pm 0.2$ & $8.1 \pm 0.3$ & $5.0 \pm 0.1$ & $22.2 / 22.0$ & $8.1 / 8.3$ & 152 & 8.4 & $45 \pm 3.8$ & $1.2 \pm 0.03$ \\
\hline August & $5.4 \pm 0.4$ & $3.7 \pm 0.1$ & $5.0 \pm 0.2$ & 22.6/22.1 & 7.4 & 158 & $6.3 / 5.5$ & $39 \pm 0.7$ & $1.2 \pm 0.09$ \\
\hline September & $8.6 \pm 0.2$ & $7.0 \pm 0.1$ & $6.3 \pm 0.3$ & 16.0 & 7.7 & 157 & 7.7 & $41 \pm 5.0$ & $1.1 \pm 0.10$ \\
\hline
\end{tabular}

Separate data for the control and the Myriophyllum verticillatum site are only given when significant differences occurred (Student's $t$-test). 
ANOVA with time as the within-subjects factor and treatment as the between-subjects factor using the statistical package SPSS. Water samples were taken from the aquaria at the end of the experiment and analyzed for soluble reactive phosphorus and nitrate following standard methods (Anonymous 1999).

\section{RESULTS}

TPC in plants and water. The TPC of M. verticillatum varied between 55 and $123 \mathrm{mg} \cdot \mathrm{g}^{-1} \mathrm{dm}$ during the growing season between May and September 2004, with apical tips containing significantly higher amounts compared with stems and leaves during the entire growing season [Fig. 1, two-way ANOVA: effect of plant part: $F_{2 ; 30}=303.5(P<0.001)$; interaction plant part $\times$ time: $F_{8 ; 30}=11.7 \quad(P<0.001)$; effect of time: $\left.F_{4 ; 30}=26.2(P<0.001)\right]$. The PVPP assays showed that $10 \%-16 \%$ of the TPC were not phenolics but other compounds. Seasonal dynamics revealed significantly higher concentrations of TPC in stems and leaves in May and significantly lower concentrations of TPC in apical tips in September (Fig. 1). TPC of the lake water were significantly lower in May and did not differ significantly between open water and $M$. verticillatum stands, except for September (Fig. 2). Excretion of phenolic compounds into the surrounding medium resulted in concentrations of TPC between $1.9 \pm 0.1$ and $5.4 \pm 0.9 \mu \mathrm{g} \cdot \mathrm{L}^{-1}$ after $24 \mathrm{~h}$. Net excretion rates per unit plant biomass were significantly higher in May and September (Fig. 2).

Bioassay with plant extracts. Extracts of the apical parts of $M$. verticillatum resulted in clearing areas in all treatments of the ADA using the cyanobacterium Anabaena PCC 7120 (Fig. 3). However, inhibition was only significantly different from control in August for the $2 \mathrm{mg} \mathrm{dm}$ treatment (ANOVA, $P=0.006$ ). No cor-

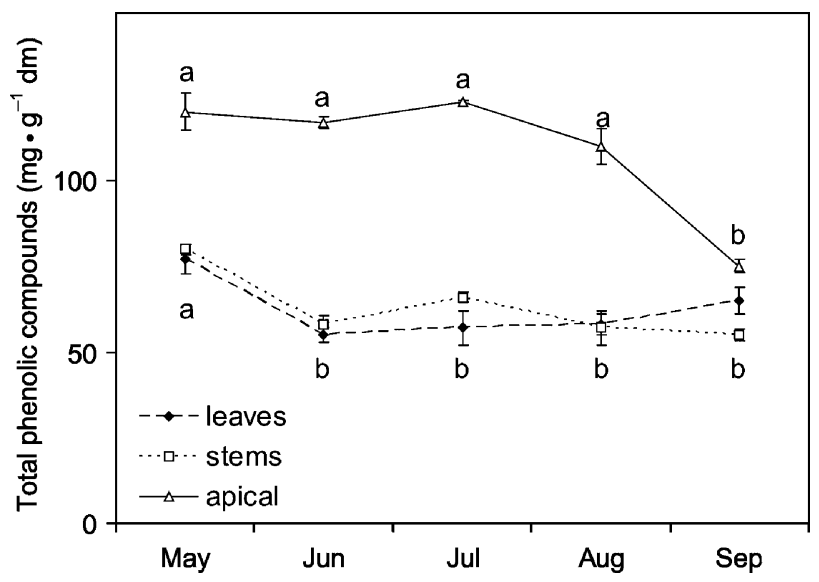

FIG. 1. Seasonal variation of the concentrations of total phenolic compounds in apical meristem, stem, and leaf tissue of the submerged plant species Myriophyllum verticillatum of Lake Krumme Laake in 2004. Values are means of three replicates \pm standard error (SE). Letters represent results of multiple comparisons between monthly means. Means sharing the same letter within one plant part are not significantly different at $P<0.05$. Results for leaves are also valid for stems.

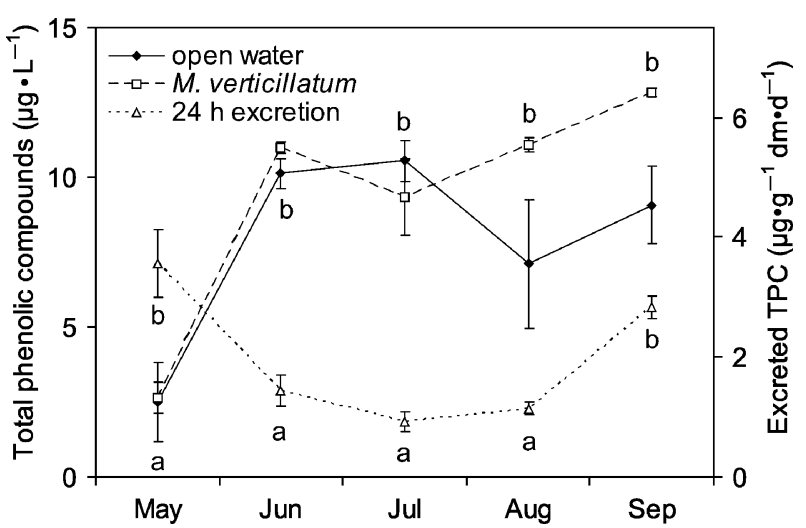

FIG. 2. Seasonal variation of the concentrations of total phenolic compounds $( \pm \mathrm{SE})$ in water of Lake Krumme Laake without (open water) and with the influence of the submerged plant species Myriophyllum verticillatum and excretion rates of 10 $M$. verticillatum shoots in $24 \mathrm{~h}$ ( $24 \mathrm{~h}$ excretion). Letters represent results of multiple comparisons between monthly means of excreted TPC. Means sharing the same letter within one curve are not significantly different at $P<0.05$.

relation was determined between the TPC and the clearing areas.

In situ experiments. When growing the different phytoplankton species for 3 days under the influence of $M$. verticillatum in Lake Krumme Laake, chl $a$ content and PSII activity were significantly higher in S. minutulus (July and September) and Scenedesmus armatus (August) compared with controls (Fig. 4). In August, chl $a$ and PSII activity were lower in the plant treatment of $S$. minutulus. L. redekei exhibited no significant differences during the whole season in $\operatorname{chl} a$, but a significantly lower PSII activity in the plant treatment in August. Rapid light curves revealed significantly higher rETR $_{\max }$ in all phytoplankton species investigated when grown between $M$. verticillatum

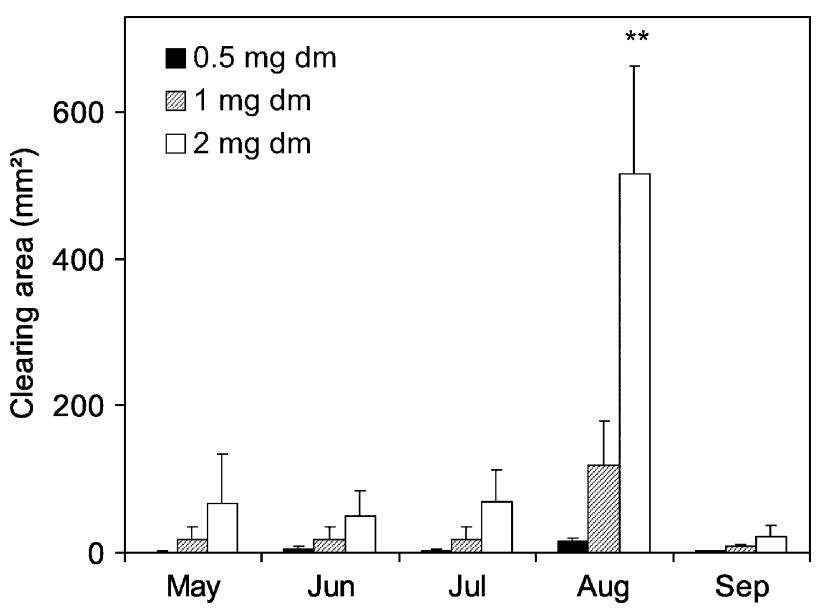

FIG. 3. Seasonal variation of the inhibition of Anabaena PCC 7120 in the ADA of different amounts of crude extract of apical parts of $M$. verticillatum. Only the $2 \mathrm{mg} \mathrm{dm}$ treatment in August proved to be significantly different from the control (ANOVA, $P=0.006)$. 


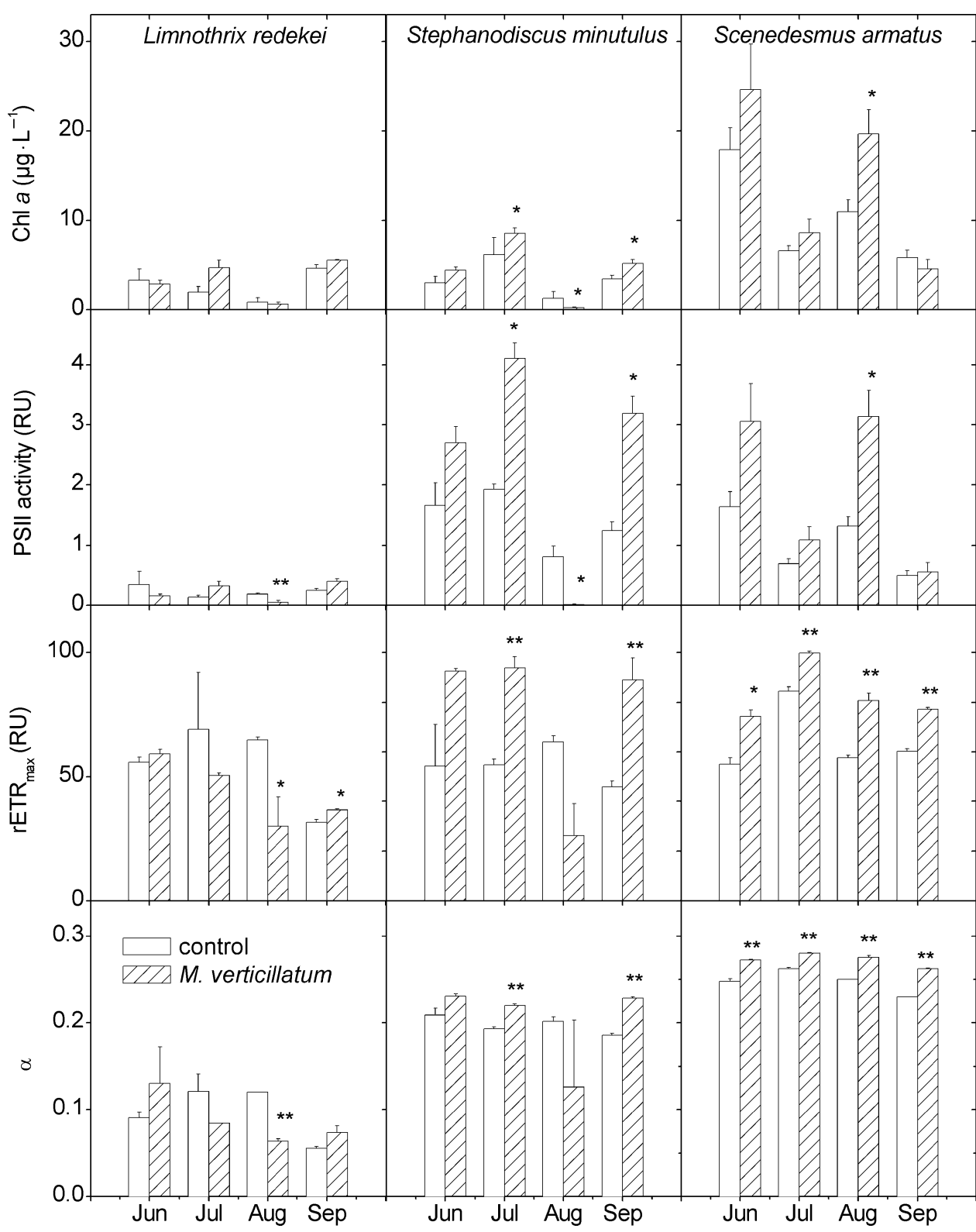

FIG. 4. Chl $a$ content, PSII activity, maximum relative electron transport rate $\left(\mathrm{rETR}_{\max }\right)$, and initial slope $(\alpha)$ of rapid light curves (Phyto-PAM fluorometer) of different phytoplankton species grown in dialysis membrane tubes for 3 days in Lake Krumme Laake without (control) and with the influence of the submerged macrophyte species Myriophyllum verticillatum. PSII activity of Scenedesmus armatus has been reduced by a factor of 10 to fit into the same scale. Values are means of three replicates $+\mathrm{SE}$, and significant differences between controls and $M$. verticillatum treatments are marked with * $(P<0.05)$ or ** $(P<0.01)$. as compared with the controls in September (Fig. 4). In August, Scenedesmus armatus showed a higher $\mathrm{rETR}_{\max }$ in the $M$. verticillatum treatment, whereas the $\mathrm{rETR}_{\max }$ of $L$. redekei was significantly lower when grown between the submerged plants. In July, S. minutulus and Scenedesmus armatus had significantly higher rETR $_{\max }$ in the plant treatments and in June, only Scenedesmus armatus showed a significantly higher value in the plant treatment. The initial slope, $\alpha$, of the rapid light curves followed the pattern of the EETR $_{\max }$ in most cases, with significantly higher $\alpha$ when rETR $_{\max }$ was higher and significantly lower $\alpha$ when rETR $_{\max }$ was lower (L. redekei in August; Fig. 4). Concentrations of soluble reactive phosphorus in Lake Krumme Laake ranged from $<3$ (detection limit) to $10 \mu \mathrm{g} \cdot \mathrm{L}^{-1}$, total phosphorus concentrations were between 28 and $52 \mu \mathrm{g} \cdot \mathrm{L}^{-1}$, ammonium concentrations between $<0.03$ (detection limit) and $0.06 \mathrm{mg} \cdot \mathrm{L}^{-1}$, nitrate concentrations were $<0.01 \mathrm{mg} \cdot \mathrm{L}^{-1}$, and total nitrogen concentrations ranged between 1.2 and $1.3 \mathrm{mg} \cdot \mathrm{L}^{-1}$ and did not differ significantly between samples of macrophyte stands and open water (Student's $t$-tests, $P>0.05)$.

Laboratory experiments on interference with P-limitation. In the laboratory experiments without P-limitation, no significant difference between $L$. redekei grown in aquaria with $M$. verticillatum and with plastic plants (controls) was detected for chl $a$ and PSII activity after 3 days, whereas P-limitation resulted in significantly higher chl $a$ in the $M$. verticillatum treatment (Fig. 5, Table 2). The $\mathrm{rETR}_{\max }$ was significantly 
decreasing during the experiment in the $M$. verticillatum treatment both with and without P-limitation. In the controls, rETR $_{\max }$ remained constant without P-limitation, but exhibited a significantly stronger decrease than the $M$. verticillatum treatment under P-limited conditions. The initial slope, $\alpha$, followed the same pattern in the experiment without P-limitation. With P-limitation, $\alpha$ was reduced during the experiment in both treatments, but significantly in the $M$. verticillatum treatment (Fig. 5, Table 2). APA increased significantly in the controls as compared with the $M$. verticillatum treatment during the experiment under P-limitation (Fig. 5, Table 2). Soluble reactive phosphorus concentrations were $4 \pm 1$ (means $\pm 1 \quad \mathrm{SD}) \mu \mathrm{g} \cdot \mathrm{L}^{-1}$ under P-limitation, $1.5 \pm$ $0.1 \mathrm{mg} \cdot \mathrm{L}^{-1}$ without P-limitation, and $\mathrm{NO}_{3}^{-}-\mathrm{N}$ concentrations $6.3 \pm 0.5 \mathrm{mg} \cdot \mathrm{L}^{-1}$ at day 3 in both experiments. These nutrient concentrations did not differ significantly between $M$. verticillatum treatment and control in each of the experiments (Student's $t$-test, $P>0.05)$.

\section{DISCUSSION}

TPC in plants and water. M. verticillatum, like other members of the Haloragaceae (Gross 1999), produces high concentrations of polyphenolic compounds of more than 5\% of $\mathrm{dm}$ in all tissues throughout the vegetated period. Polyphenol concentrations were significantly higher in the apical meristem, reaching $123 \mathrm{mg} \cdot \mathrm{g}^{-1} \mathrm{dm}$, comparable with M. spicatum (Gross 2000). The latter can reach TPC of $150-300 \mathrm{mg} \cdot \mathrm{g}^{-1} \mathrm{dm}$ (E. M. Gross, unpublished data). Polyphenols in M. spicatum have been shown to allelopathically inhibit algae and cyanobacteria (Gross et al. 1996, Leu et al. 2002). Compared with the high TPC tissue concentrations in M. verticillatum, excretion rates seem low but might be underestimated due to rapid microbial and photolytic decomposition (Gross 2003a). In spring, TPC tissue concentrations in $M$. verticillatum as well as the excretion rate of polyphenolic compounds into the surrounding water were the highest (Figs. 1 and 2). Also in M. verticillatum, polyphenols account for allelopathic interference (Aliotta et al. 1991). The high TPC concentration in spring thus seems ecologically plausible for this rooted submerged plant as competition for light with phytoplankton might be the strongest in spring when plants start growing from the lake bottom. Gross (2000), however, measured high TPC concentrations in M. spicatum throughout the season, and Godmaire and Planas (1986) observed a stimulatory effect of $M$. spicatum on the productivity of a mixed phytoplankton community during the phase when the macrophyte was actively growing. A study on factors controlling the intraspecific variability of polyphenols in $M$. spicatum revealed a strong positive effect of light (Gross 2003b), and in Lake Krumme Laake, water transparency indeed was the highest in spring and early

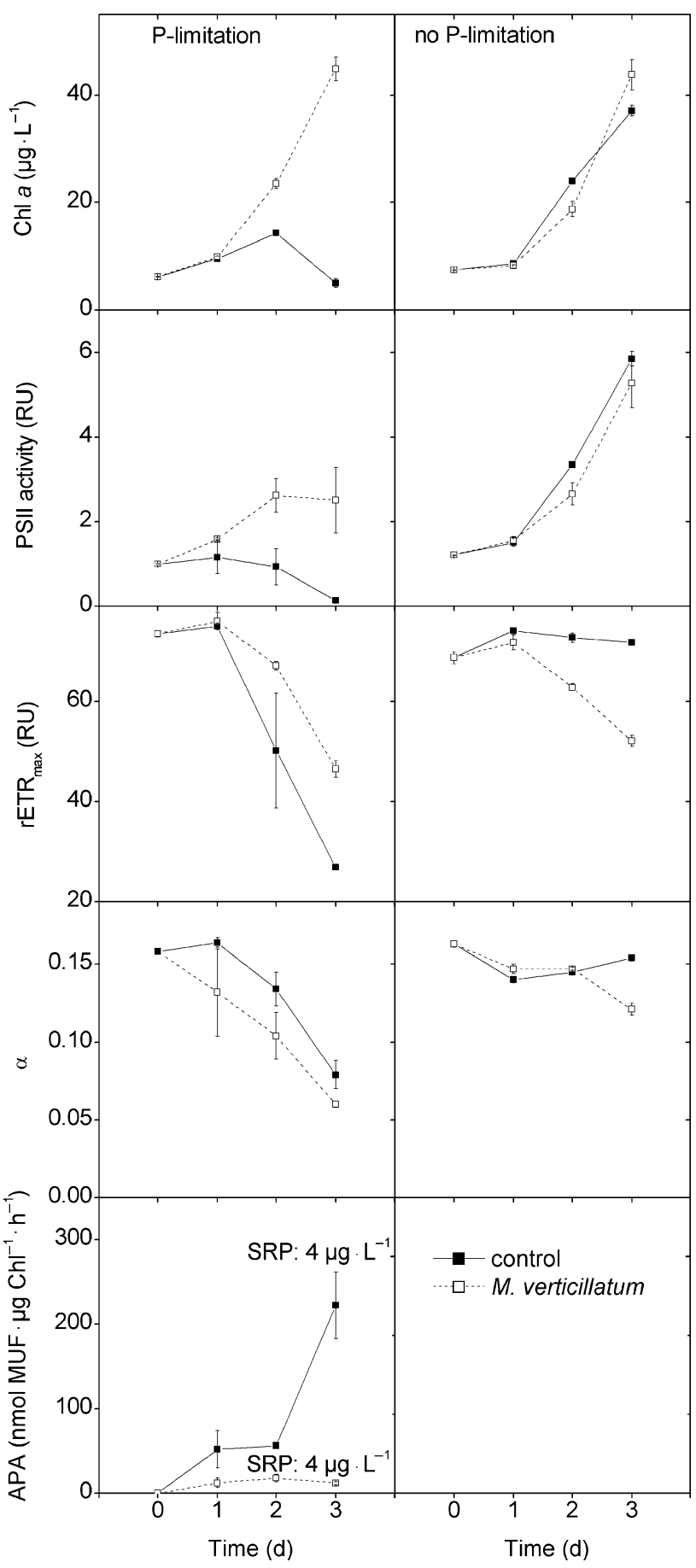

FIG. 5. Chl $a$ content, PSII activity, $\mathrm{rETR}_{\max }$, initial slope $(\alpha)$, and alkaline phosphatase activity (APA; \pm SE) of the cyanobacteria Limnothrix redekei grown in dialysis membrane tubes in nutrient solution with (left column) and without phosphorus limitation (right column) under the influence of Myriophyllum verticillatum as compared with controls with plastic plants. Soluble reactive phosphorus (SRP) concentrations at day 3 are given for the experiment with P-limitation. APA was 0 in the experiment without P-limitation (MUF: methylumbelliferone). The results of the repeated measures ANOVA are given in Table 2. 
TABLE 2. Differences in growth and photosynthesis characteristics of Limnothrix redekei grown in dialysis membrane tubes in nutrient solution for 3 days under the influence of Myriophyllum verticillatum as compared with control treatments with plastic plants using a repeated measures analysis of variance with time as the within-subjects factor and treatment as the betweensubjects factor.

\begin{tabular}{|c|c|c|c|}
\hline Parameter & Effect of & P-limitation & No P-limitation \\
\hline \multirow[t]{3}{*}{ Chl $a$} & Time & $F_{3 ; 12}=58.1 \quad(P<0.001)$ & $F_{3 ; 12}=299.0(P<0.001)$ \\
\hline & Time $\times$ treatment & $F_{3 ; 12}=78.7 \quad(P<0.001)$ & $F_{3 ; 12}=7.57 \quad(P<0.004)$ \\
\hline & Treatment & $F_{1: 4}=51.3 \quad(P<0.002)$ & $F_{1: 4}=0.123 \quad(P<0.744)$ \\
\hline \multirow[t]{3}{*}{ PSII activity } & Time & $F_{3 ; 12}=2.13 \quad(P<0.150)$ & $F_{3 ; 12}=131.7(P<0.001)$ \\
\hline & Time $\times$ treatment & $F_{3 ; 12}=6.10 \quad(P<0.009)$ & $F_{3 ; 12}=1.204(P<0.350)$ \\
\hline & Treatment & $F_{1 ; 4}=10.05(P<0.034)$ & $F_{1: 4}=3.80(P<0.123)$ \\
\hline \multirow{3}{*}{$\mathrm{rETR}_{\max }$} & Time & $F_{3 ; 12}=30.31(P<0.001)$ & $F_{3 ; 12}=36.32(P<0.001)$ \\
\hline & Time $\times$ treatment & $F_{3 ; 12}=2.14 \quad(P<0.148)$ & $F_{3 ; 12}=34.54(P<0.001)$ \\
\hline & Treatment & $F_{1: 4}=17.69(P<0.014)$ & $F_{1: 4}=201.1(P<0.001)$ \\
\hline \multirow[t]{3}{*}{$\alpha$} & Time & $F_{3 ; 12}=25.00(P<0.001)$ & $F_{3 ; 12}=34.22(P<0.001)$ \\
\hline & Time $\times$ treatment & $F_{3 ; 12}=0.877(P<0.480)$ & $F_{3 ; 12}=23.25(P<0.001)$ \\
\hline & Treatment & $F_{1 ; 4}=3.843(P<0.122)$ & $F_{1 ; 4}=16.82(P<0.015)$ \\
\hline \multirow{3}{*}{ Alkaline phosphatase activity } & Time & $F_{3 ; 12}=25.60(P<0.001)$ & \\
\hline & Time $\times$ treatment & $F_{3 ; 12}=22.84(P<0.001)$ & \\
\hline & Treatment & $F_{1 ; 4}=124.2(P<0.001)$ & \\
\hline
\end{tabular}

rETR, relative electron transport rate.

summer (S. Hilt, unpublished results). In May, however, the apical tips of $M$. verticillatum were approximately $50 \mathrm{~cm}$ below the water surface, whereas plants reached the water surface during the rest of the season. Thus, factors other than light might have determined the TPC and hence the potential allelopathic activity of $M$. verticillatum in Lake Krumme Laake. Higher excretion rates at the end of the season in September can probably be explained by senescence. In general, milfoil polyphenols possess a wide biological activity against insect herbivores, algae, cyanobacteria, and heterotrophic bacteria and may also be involved in UV protection (Rozema et al. 1997, Gross 2003a).

The increase in TPC in the water samples of Lake Krumme Laake in summer is probably a consequence of an influx of humic compounds from a surrounding peat bog as a consequence of a falling water level (due to the use of groundwater for drinking water supply in the catchment) and mineralization. The slightly dystrophic character of the lake might be the reason for the lack of significant differences in TPC between the water in the $M$. verticillatum stands and the open water. During senescence of the plants in September, significantly higher values were measured in the water of the $M$. verticillatum stands (when only comparing means of September using Student's $t$-test at $P<0.05$ ). Allochthonous humic compounds may have interfered with the allelopathic action of polyphenols excreted by $M$. verticillatum, as dissolved humic substances might also affect phytoplankton growth and composition (Serrano and Guisande 1990, Carlsson et al. 1995). These measurements show that field studies investigating the release of allelopathically active compounds need to be accompanied by laboratory studies using controlled conditions to distinguish between plant- and lake-water-related effects (Gross et al. in press).

Bioassay with plant extracts. The inhibitory activity of the crude extracts of apical parts to a cyanobacte- rium underlines the allelopathic potential of $M$. verticillatum. The significant activity in August was in the same range as found for M. spicatum (Lutz 2004). The lack of correlation between the clearing areas and the TPC suggests the occurrence of an allelopathically active polyphenolic compound with a seasonal variability different from that of the TPC; synergistic effects of polyphenolic compounds (Aliotta et al. 1992); or the contribution of other, nonpolyphenolic active substances.

In situ experiments. Our field experiments reveal for the first time the allelopathic effects of $M$. verticillatum under in situ conditions. Parameters like water temperature, $\mathrm{pH}$, or oxygen content did not differ significantly between the control and the $M$. verticillatum stands in most cases (Table 1) and are unlikely to account for the observed effects.

In situ experiments seem to support the findings of the bioassay that the allelopathic-inhibitory potential of $M$. verticillatum against phytoplankton was the greatest in August. A significant inhibition of chl $a$ and PSII activity of the target species in situ was only observed in August and only for L. redekei and S. minutulus, whereas Scenedesmus armatus (and S. minutulus in July and September) were even stimulated. Cyanobacteria and the diatom have been more sensitive than the green alga Scenedesmus armatus when grown under the influence of M. spicatum (Körner and Nicklisch 2002). Cyanobacteria seem especially susceptible to allelopathic substances of aquatic macrophytes (Aliotta et al. 1991, Jasser 1995, Erhard and Gross 2006) and stimulatory allelopathic effects on green algae were frequently observed (Jasser 1995, Erhard and Gross 2006, Mulderij et al. in press). Mechanisms explaining these differences, however, are still unknown. Different minimum effect concentrations might be one reason. Rice (1984) stated that certain allelochemicals may stimulate target organisms at very low concentrations but inhibit at higher concentrations. 


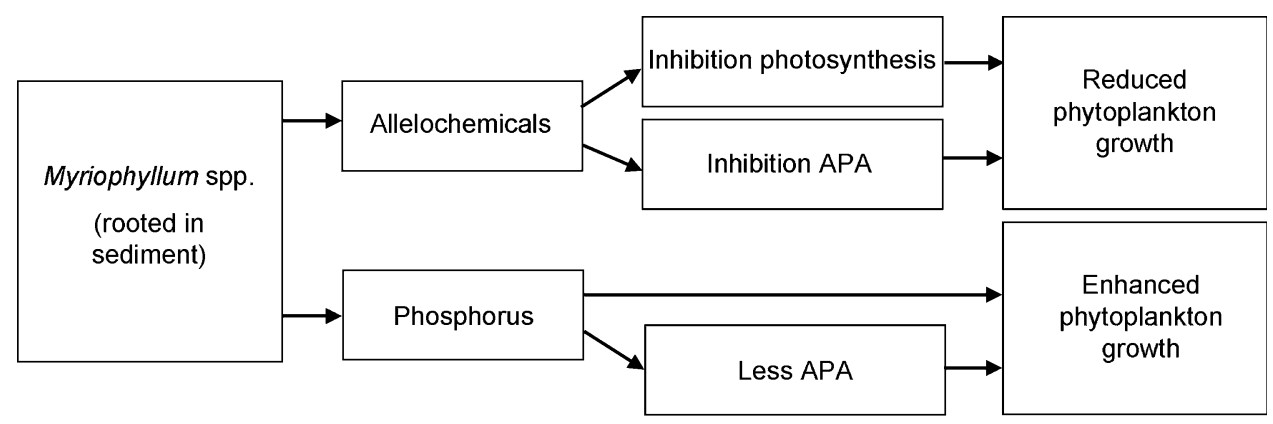

FIG. 6. Scheme of the potential influence of Myriophyllum species on phytoplankton via excreted allelochemicals and phosphorus.
Possible explanations for the observed patterns in the field are (1) seasonality of composition of active compounds: Comparable with our observations in the agar diffusion bioassay, seasonal changes in the total amount and composition of the yet unknown allelopathically active substances among the TPC excreted by $M$. verticillatum may have resulted in seasonal changes of allelopathic effects in the dialysis bag field experiments. A detailed analysis of the active compounds in M. verticillatum and their effects is needed to further elucidate their potential effects on growth and photosynthetic activity of phytoplankton species. Preliminary results indicate that polyphenols other than the phenylpropanoid glucosides discussed by Aliotta et al. (1992) and other than tellimagrandin II, the major allelochemical in M. spicatum (Gross et al. 1996), account for the observed activity in our experiments (E. M. Gross unpublished results). (2) Starting concentration/ growth rates of target phytoplankton species: An inhibition of $\operatorname{chl} a$, PSII activity, ETRR $_{\max }$, and $\alpha$ was only observed in August, when growth rates (calculated using chl $a$ at the beginning and end of the experiments) were 0 in L. redekei and S. minutulus even at the control sites. Allelopathy is considered to be especially effective in stress situations (Reigosa et al. 1999), leading to our conclusion that a yet unknown additional stressor prevented L. redekei and S. minutulus from growing in August and might have resulted in a significant effect of allelochemicals released by $M$. verticillatum. For S. minutulus, the starting cell density was the lowest in August (Table 1), which also might have influenced the response (e.g. due to a longer lag phase). Further, an interference with nutrient availability [see (3) below] apparently does not play a role when growth rates are 0 . (3) Interference with nutrient availability: For the inhibition of phytoplankton by milfoil polyphenols, two modes of action have been proposedphotosynthesis inhibition (Körner and Nicklisch 2002, Leu et al. 2002) and inhibition of alkaline phosphatase (APA, Gross et al. 1996). The latter is only relevant when P-limitation of phytoplankton growth occurs, which was likely for Lake Krumme Laake due to $\mathrm{N}: \mathrm{P}$ ratios between 30 and 40. Myriophyllum plants and their epiphyton, however, leak and release phosphorus during decomposition (Barko and Smart 1980, Howard-Williams and Allanson 1981, Carignan and Kalff 1982, Smith and Adams 1983), so that the phytoplankton growth may directly be enhanced in the plant stands and less alkaline phosphatase might be produced. This possibility may lead to enhanced phytoplankton growth in the plant stands compared with the control site and hence compensate and therewith mask the negative allelopathic effects of the plants on the phytoplankton (Fig. 6).

The potential effects of this compensation were demonstrated in the aquarium experiments using $L$. redekei as an example. M. verticillatum clearly showed an allelopathic effect on L. redekei without P-limitation by a significantly lower $\mathrm{rETR}_{\max }$ in the plant treatment as compared with the control (Fig. 5, right column). Comparable effects had been observed for C. demersum (Körner and Nicklisch 2002). With P-limitation, this effect is masked, because rETR $_{\max }$ in the control was even further reduced than in the plant treatment (Fig. 5 , left column). This was most probably due to $\mathrm{P}$ leakage of $M$. verticillatum and direct usage of this $\mathrm{P}$ by L. redeke $i$ in the plant treatment and a resultant stronger P-limitation in the control, as (a) the APA was higher in the control treatment despite comparable concentrations of soluble reactive phosphorus in treatment and control $\left(4 \mu \mathrm{g} \cdot \mathrm{L}^{-1}\right)$, (b) nutrient limitation also leads to a decline in the PSII quantum efficiency (Kromkamp and Peene 1999, Lippemeier et al. 2003), and (c) L. redekei had a significantly higher growth rate (based on $\operatorname{chl} a$ ) in the plant treatment.

We conclude that allelochemicals produced and exuded by $M$. verticillatum most likely cause an allelopathic inhibition of certain phytoplankton species as demonstrated for the tested cyanobacteria and the diatom, while others, like the tested green alga, may be stimulated. Laboratory experiments supported the potential interference of nutrient competition and allelopathic effects, and thus a mechanism that potentially prevented the detection of the real extent of allelopathic activities under nutrient limitation in situ. Future in situ studies need to exclude any potential differences in nutrient availability between control and plant treatment (e.g. by ensuring a surplus of nutrients from diffusing substrates).

We are grateful to Lina Wischnewsky for helping with the PAM measurements and maintenance of algal cultures, Rüdiger Biskupek for help during field sampling, Helgard Täuscher for the determination and counting of phytoplankton species from field samples, Christiane Herzog, Antje Lüder, Elke Zwirnmann, Hans-Jürgen Exner, and Thomas Rossoll (IGB) for determination of nutrient concentrations, 
Claudia Feldbaum (University of Konstanz) for assisting with TPC and PVPP measurements, and Andreas Nicklisch (Humboldt University Berlin) for scientific discussions. We very much appreciate constructive comments by two anonymous reviewers on a previous version of this manuscript. S. H. was financially supported by the "Berliner Programm zur Förderung der Chancengleichheit von Frauen in Forschung und Lehre" and M. G. by a travel grant from the German Research Foundation (DFG 445 AGY-112/33/04). Research at the University of Konstanz during a guest stay of S. H. was supported by the German Research Foundation (SFB 454, project A2 to E. M. G.).

Aliotta, G., Molinaro, A., Monaco, P., Pinto, G. \& Previtera, L 1992. Three biologically active phenylpropanoid glucosides from Myriophyllum verticillatum. Phytochemistry 31:109-11.

Aliotta, G., Monaco, P., Pinto, G., Pollio, A. \& Previtera, L. 1991. Potential allelochemicals from Pistia stratiotes L. J. Chem. Ecol. $17: 2223-34$.

Anonymous 1999. Deutsche Einheitsverfahren zur Wasser-, Abwasserund Schlamm-Untersuchung. Verlag Chemie, Weilheim, Germany.

Anthoni, U., Christophersen, C., Madsen, J., Wium-Andersen, S. \& Jacobsen, N. 1980. Biologically active sulphur compounds from the green alga Chara globularis. Phytochemistry 19:1228-9.

Barko, J. W. \& Smart, R. M. 1980. Mobilization of sediment phosphorus by submersed freshwater macrophytes. Freshw. Biol. 10:229-38.

Carignan, R. 1982. An empirical model to estimate the relative importance of roots in phosphorus uptake by aquatic macrophytes. Can. J. Fish. Aquat. Sci. 39:243-7.

Carignan, R. \& Kalff, J. 1982. Phosphorus release by submerged macrophytes: significance to epiphyton and phytoplankton. Limnol. Oceanogr. 27:419-27.

Carlsson, P., Graneli, E., Tester, P. \& Boni, L. 1995. Influences of riverine humic substances on bacteria, protozoa, phytoplankton, and copepods in a coastal plankton community. Mar. Ecol. Prog. Ser. 127:213-21.

DeMarte, J. A. \& Hartman, R. T. 1974. Studies on the absorption of ${ }^{32} \mathrm{P},{ }^{59} \mathrm{Fe}$ and ${ }^{45} \mathrm{Ca}$ by water-milfoil. Ecology $55: 188-94$.

Erhard, D. \& Gross, E. M. 2006. Allelopathic activity of Elodea canadensis and E. nuttallii against epiphytes and phytoplankton. Aquat. Bot. 85:203-11.

Fitzgerald, G. P. 1969. Some factors in the competition or antagonism among bacteria, algae and aquatic weeds. J. Phycol. 5:351-9.

Godmaire, H. \& Planas, D. 1986. Influence of Myriophyllum spicatum on the species composition, biomass and primary productivity of phytoplankton. Aquat. Bot. 23:299-308.

Grace, J. B. \& Wetzel, R. G. 1978. The production biology of Eurasian watermilfoil (Myriophyllum spicatum L.): a review. J. Aquat. Plant Manag. 16:1-11.

Gross, E. M. 1999. Allelopathy in benthic and littoral areas: case studies on allelochemicals from benthic cyanobacteria and submersed macrophytes. In Inderjit, Dakshini, K. M. M. \& Foy, D. [Eds.] Principles and Practices in Plant Ecology: Allelochemical Interactions. CRC Press, Boca Raton, pp. 179-99.

Gross, E. M. 2000. Seasonal and spatial dynamics of allelochemicals in the submersed macrophyte. Verh. Internat. Verein. Limnol. $27: 2116-9$

Gross, E. M. 2003a. Allelopathy of aquatic autotrophs. Crit. Rev. Plant Sci. 22:313-39.

Gross, E. M. 2003b. Differential response of tellimagrandin II and total bioactive hydrolysable tannins in an aquatic angiosperm to changes in light and nitrogen. Oikos 103: 497-504.

Gross, E. M., Hilt, S., Lombardo, P. \& Mulderij, G. 2007. Searching for allelopathic effects of submerged macrophytes on phytoplankton-State of the art and open questions. Hydrobiologia. (in press)
Gross, E. M., Meyer, H. \& Schilling, G. 1996. Release and ecological impact of algicidal hydrolysable polyphenols in Myriophyllum spicatum. Phytochemistry 41:133-8.

Gross, E. M., Wolk, C. P. \& Jüttner, F. 1991. Fischerellin, a new allelochemical from the freshwater cyanobacterium Fischerella muscicola. J. Phycol. 27:686-92.

Howard-Williams, C. \& Allanson, B. R. 1981. Phosphorus cycling in a dense Potamogeton pectinatus L. bed. Oecologia 49:56-66.

Jackson, L. J., Rowan, D. J., Cornett, R. J. \& Kalff, J. 1994. Myriophyllum spicatum pumps essential and nonessential trace elements from sediments to epiphytes. Can. J. Fish. Aquat. Sci. 51:1769-73.

Jasser, I. 1995. The influence of macrophytes on a phytoplankton community in experimental conditions. Hydrobiologia 306: 21-32.

Körner, S. \& Nicklisch, A. 2002. Allelopathic growth inhibition of selected phytoplankton species by submerged macrophytes. J. Phycol. 38:862-71.

Kromkamp, J. \& Peene, J. 1999. Estimation of phytoplankton photosynthesis and nutrient limitation in the Eastern Scheldt estuary using variable fluorescence. Aquat. Ecol. 33: $101-4$.

Kufel, L. \& Ozimek, T. 1994. Can Chara control phosphorus cycling in Lake Luknajno (Poland)? Hydrobiologia 275/276: 277-83.

Leu, E., Krieger-Liszkay, A., Goussias, C. \& Gross, E. M. 2002. Polyphenolic allelochemicals from the aquatic angiosperm Myriophyllum spicatum L. inhibit photosystem II. Plant Physiol. 130:2011-8.

Lippemeier, S., Frampton, D. M. F., Blackburn, S. I., Geier, S. C. \& Negri, A. P. 2003. Influence of phosphorus limitation on toxicity and photosynthesis of Alexandrium minutum (Dinophyceae) monitored by in-line detection of variable chlorophyll fluorescence. J. Phycol. 39:320-31.

Lombardo, P. \& Cooke, G. D. 2003. Ceratophyllum demersum phosphorus interactions in nutrient enriched aquaria. Hydrobiologia 497:79-90.

Loomis, W. D. \& Battaile, J. 1966. Plant phenolic compounds and the isolation of plant enzymes. Phytochemistry 5:423-38.

Lutz, S. 2004. Analysis of phenolic secondary metabolites in Myriophyllum spp. (Haloragaceae). Diploma thesis, University of Konstanz, Konstanz, Germany, 101 pp.

Mulderij, G., Mau, B., van Donk, E. \& Gross, E. M. 2007. Allelopathic activity of Stratiotes aloides on phytoplanktontowards identification of allelopathic substances. Hydrobiologia. (in press)

Nakai, S., Inoue, Y., Hosomi, M. \& Murakami, A. 1999. Growth inhibition of blue-green algae by allelopathic effects of macrophytes. Water Sci. Technol. 39:47-53.

Nicklisch, A. 1992. The interaction of irradiance and temperature on the growth rate of Limnothrix redekei and its mathematical description. Arch. Hydrobiol. 91(Suppl, Algological Studies 63): $1-18$

Phillips, G. L., Eminson, D. \& Moss, B. 1978. A mechanism to account for macrophyte decline in progressively eutrophicated freshwaters. Aquat. Bot. 4:103-26.

Rattray, M. R., Howard-Williams, C. \& Brown, J. M. A. 1991. Sediment and water as sources of nitrogen and phosphorus for submerged rooted aquatic macrophytes. Aquat. Bot. 40: $225-37$.

Reigosa, M. J., Sanchez-Moreiras, A. \& Gonzalez, L. 1999. Ecophysiological approach in allelopathy. Crit. Rev. Plant Sci. 18:577-608.

Rice, E. L. 1984. Allelopathy. 2nd ed. Academic Press, Orlando, FL. $422 \mathrm{pp}$.

Rozema, J., Van de Staaij, J., Bjorn, L. O. \& Caldwell, M. 1997. UV-B as an environmental factor in plant life: stress and regulation. Trends Ecol. Evol. 12:22-8.

Scheffer, M. 1998. Ecology of Shallow Lakes. Chapman \& Hall, London, 357 pp.

Schreiber, U. 1986. Detection of rapid induction kinetics with a new type of high frequency modulated chlorophyll fluorometer. Photosynth. Res. 9:261-72. 
Schreiber, U., Bilger, W. \& Neubauer, C. 1994. Chlorophyll fluorescence as a non-intrusive indicator for rapid assessment of in vivo photosynthesis. Ecol. Stud. 100:47-70.

Serrano, L. \& Guisande, C. 1990. Effects of polyphenolic compounds on phytoplankton. Int. Ver. Theor. Angew. Limnol. Verh. 24:282-8.

Smith, C. S. \& Adams, M. S. 1983. Phosphorus transfer from sediments by Myriophyllum spicatum. Limnol. Oceanogr. 31: 1312-21.

Van Donk, E., Gulati, R. D., Iedema, A. \& Meulemans, J. T. 1993. Macrophyte-related shifts in the nitrogen and phosphorus contents of the different trophic levels in a biomanipulated shallow lake. Hydrobiologia 251:19-26.

Van Donk, E. \& Van de Bund, W. 2002. Impact of submerged macrophytes including charophytes on phyto- and zooplankton communities: allelopathy versus other mechanisms. Aquat. Bot. 72:261-74.

Willis, R. J. 1985. The historical bases of the concept of allelopathy. J. Hist. Biol. 18:71-102.

Wium-Andersen, S., Anthoni, U. \& Houen, G. 1983. Elemental sulphur, a possible allelopathic compound from Ceratophyllum demersum. Phytochemistry 22:2613. 